\title{
Digital Scholarship Considered: How New Technologies Could Transform Academic Work
}

\author{
Nick Pearce, Martin Weller, Eileen Scanlon, and Melanie Ashleigh
}

The Open University

\begin{abstract}
New digital and web-based technologies are spurring rapid and radical changes across all media industries. These newer models take advantage of the infinite reproducibility of digital media at zero marginal cost. There is an argument to be made that the sort of changes we have seen in other industries will be forced upon higher education, either as the result of external economic factors (the need to be more efficient, responsive, etc.) or by a need to stay relevant to the socalled "net generation" of students (Prensky, 2001; Oblinger \& Oblinger, 2005; Tapscott \& Williams, 2010).

This article discusses the impact of digital technologies on each of Boyer's dimensions of scholarship: discovery, integration, application and teaching. In each case the use of new technologies brings with it the possibility of new, more open ways of working, although this is not inevitable. The implications of the adoption of new technologies on scholarship are then discussed.
\end{abstract}

Keywords: internet; digital technology; technology in education; social media; higher education; Web 2.0 


\section{Digital Scholarship Considered: How New Technologies Could Transform Academic Work}

New digital and web-based technologies are spurring rapid and radical changes across all media industries. Business models in music, film, newspaper, and television established around physical goods and an economy of scarcity are being challenged by an array of new models based on digital goods and services and an economy of abundance, where digital artefacts can be endlessly reproduced at little or no cost. We have thus witnessed declining newspaper sales yet a general failure, to date, to transfer the subscription business model online through fees. There are frequent references in the news to the threat of illegal downloads to the music industry, whilst legal digital downloads have rapidly made inroads into physical sales, comprising $27 \%$ of the global market in 2009, a proportion which is rising rapidly (IFPI, 2010).

These newer models take advantage of the infinite reproducibility of digital media at zero marginal cost. Once digitized, these media can be shared almost instantly and freely, and whilst this poses a challenge for private companies built on the ownership of physical data and media, it also creates possibilities for openness and transparency. Individuals with access to the Internet can freely listen to any track or film, or get their news from any source. Whilst censorship certainly exists in some countries, this is coming under attack from a pervasive global open ideology.

New business models are emerging around streaming music with adverts (for example Spotify) where access to resources hosted in the "cloud" is paid for by advertisers or rented to subscribers, rather than physically sold as CDs. Indeed, so radical has the change been in many sectors that it could be argued that the new digital versions of these industries have more in common with each other than they do with the pre-digital versions of their industries.

However, none of these changes are inevitable and old technologies will persist; even if radically changed by newer ones. The pace of change is variable across countries, industries, and individuals. Academia is in some regards at the forefront of technological development (e.g. the development of the world wide web protocols at CERN or the early adoption of desktop computers (Shields, 1995)) but in other areas is a long way behind the commercial sector and even in teaching and learning the impact of new technologies has not been as widespread or transformative as predicted (Conole, 2004; Blin \& Munro, 2008).

One area where this clash between business models is particularly germane is academic journal publishing. The journal market is substantial, worth $\$ 65$ bn. in 2004 and dominated by 12 publishing corporations (Cope \& Kalantzis, 2009; Peters, 2009). This income is derived from library subscriptions, but as the number of journals has increased and subscriptions rates have risen libraries are faced with a journals crisis as budgets are increasingly stretched. The publishers have moved from printing physical journals to selling subscriptions to online versions of the same journal for a similar price, reducing their costs and raising their profits without changing their business practices despite the considerable opportunities afforded by digital technology (Cope \& Kalantzis, 2009). There is an increasing tension as the established business models are challenged by the opportunities presented through new technologies and we will discuss these in a later section, but it is worth emphasizing that so far the established business models and even publishing conventions have remained the same despite the adoption of new technologies.

The variable pace of technological adoption and change within higher education can be seen as the result of several factors: education has more components than a pure content industry, 
such as assessment and accreditation; that higher education qualifications such as the undergraduate degree have a social capital that is not easily changed; that there is a fundamental conservatism in and around higher education.

An argument can be made that the sort of changes seen in other industries will be forced upon higher education, either as the result of a external economic factors (the need to be more efficient, responsive, etc.), or by a need to stay relevant to the so-called "net generation" of students (Prensky, 2001; Oblinger \& Oblinger, 2005; Tapscott \& Williams, 2010).

Scholars working within universities are already interacting with new technologies and adopting new tools into their working practices (e.g. Twitter, Instant Messaging, blogs) on an ad hoc basis (Pearce forthcoming). This paper will set out to establish a definition of digital scholarship based on previous work on scholarship. It will then explore how digital technologies are creating new possibilities for open practice, and then discuss the implications of this for future practice.

\section{Digital Scholarship: New Forms of Work for New Tools?}

In 1990, Ernest Boyer produced a seminal report, "Scholarship Reconsidered”, which sought to discover which activities of the university staff were the most highly prized (Boyer, 1990, p. xi). The key issue he sought to address was how to maintain quality and focus on teaching in a higher education sector that still bases recruitment and promotion primarily on research outputs. This issue is still relevant in the UK higher education sector today.

In response he suggests:

What we urgently need today is a more inclusive view of what it means to be a scholar--a recognition that knowledge is acquired through research, through synthesis, through practice, and through teaching. (Boyer, 1990, p. 24)

These ideas are refined and developed to provide a definition of scholarship with four components, each of which Boyer thought should be considered as of equal value by universities and government policy. In the first case, scholarship is about discovery, the creation of new knowledge in a specific area or discipline. This is probably closest to the public conception of scholarship, as universities are often the site of significant breakthroughs and inventions and this is often taken to be largely synonymous with research.

Secondly, scholarship includes integration, which is still about creating knowledge but this time across disciplines. In particular, this strand of scholarship is about placing individual discoveries within a wider context. This is specifically related to work that is multi- or interdisciplinary.

These two strands of scholarship are what are recognized and reinforced through the Research Assessment Exercise (RAE), and the new Research Excellence Framework (REF) upon which recruitment and promotion within universities in the UK depends, at least in research intensive universities (but increasingly across the sector). Boyer (1990) argues for the inclusion of two further dimensions, the first of which is application, that is an engagement with the wider world outside academia, but still based on the scholar's disciplinary knowledge and background. This might include public engagement activities as well as input into policy and general media discussions. This can also include the time spent peer reviewing journal articles and grant applications and sitting on various committees. 
The final strand of scholarship is teaching which historically took precedence in the US but has since slipped from the priorities as elsewhere. The role and importance of teaching in higher education today is still hotly contested and has become increasingly important in the UK context since the introduction of tuition fees. This has seen a shift in perception from student to consumer, which has been followed by raised expectations about the quality and even quantity of teaching.

Overall, Boyer's (1990) emphasis is on the individual scholar and his conception of scholarship is based on this. By focussing on the individual scholar Boyer's conception is arguably most appropriate in the humanities with a higher incidence of lone scholars and a culture of "possessive individualism" (Rosenzweig, 2007) and social sciences, and least applicable in the natural sciences which are often characterized by large scale, capital intensive collaborations (Galison \& Hevly, 1992). In these large collaborations, there is a greater degree of specialization and division of labour. Individual scholars do not participate in the scholarly process as much as groups and teams of scholars which creates problems in itself in terms of managing the collaborations and attributing and incentivizing reward.

A recent book by Christine Borgman (2007) discusses digital scholarship with the latter type of scholar in mind where large distributed teams of scholars have been facilitated by new technologies:

The internet lies at the core of an advanced scholarly information infrastructure to facilitate distributed, data and information-intensive collaborative research. (Borgman, 2007, xvii)

Clearly when Borgman (2007) talks about "distributed, data and information-intensive collaborative research" she is thinking primarily of the kinds of scientific research that can be characterised in this way, excluding those such as theoretical physicists who work in different ways. Even when discussing social sciences and humanities, her conception of digital scholarship prioritises the computational aspects of these areas such as text mining in the humanities over other forms (see Wouters \& Beaulieu, 2006; Pieri, 2009 for more on this).

When Borgman (2007) is talking about the technologies being used by researchers she is thinking of large-scale infrastructure rather than the ad hoc adoption of Web 2.0 tools;

These are not small, local technologies that will be replaced quickly. Rather, they are large-scale international investments in an infrastructure that is expected to be in place for a long time. (p. 2)

The culture of specific fields and the epistemology of their subject may affect the organization of the field and the way in which they adopt different technologies (Whitley, 1984; Fry, 2004; Fry, 2006; Fry \& Talja, 2007). Thus, fields where there is a high level of task uncertainty, that is little agreement over the theoretical and practical research priorities and low levels of mutual dependence where researchers have little use for the outputs of others, will foster an individualistic culture which will affect the way they adopt technology:

[academic] fields that have a highly politicized and tightly controlled research culture will develop a coherent field-based strategy for the uptake and use of ICTs, whereas domains that are pluralistic and have a loosely organized research culture will appropriate ICTs in an ad-hoc localized manner. (Fry, 2004, p. 303) 
There is a substantial literature exploring the relationship between disciplines/fields and technological adoption (Kling \& McKim, 2000; Walsh, Kucker, Maloney, \& Gabbay, 2000; Barjak, 2006). These studies demonstrate some evidence for the existence of disciplinary differences in technology adoption, which suggests that there is not a homogeneous form of "scholarship" within academia.

Towards the end of "Scholarship in the Digital Age" there is a convergence with Boyer (1990) when Borgman (2007) discusses how current promotion and tenure practices at universities prioritise the established forms of scholarship;

Universities and higher education agencies risk undermining their efforts to reform scholarly communication if they merely reinforce the norms that serve print publication and that preserve the disciplinary boundaries of the past. (Borgman, p. 240)

For the purposes of this paper we will take the Boyer (1990) definition as a starting point, and in particular his four dimensional view of scholarship, whilst contextualising this within broader debates about the collaborative nature of much academic work, and the increasingly varied outputs of that work (such as including data as a research output).

Just as the move to digital media has created opportunities for more openness and transparency in the public sphere so too do new technologies hold the promise of more openness in academia.

The concept of "openness" in education is also one that has been allied with the use of new technologies, and the 'open scholar' has emerged to include a wider array of functions (Anderson, 2009; Burton, 2009). We will use the concept of openness to explore the changes in respect of Boyer's four functions.

\section{Discovery: Open Data}

Boyer's (1990) first dimension of scholarship is the discovery of new knowledge in a specific discipline or area, which will often result in the creation of data. The role of computing and the ability to both generate and analyse unprecedented amounts of data has significantly re-moulded many arenas of scientific research. The development and adoption of digital data has led to the establishment of new (sub) fields so that "[a] growing number of sciences, from atmospheric modelling to genomics, would not exist in their current form if it were not for computers" (Foster, 2006).

In addition, these digital data forms can be easily shared with colleagues and the wider academic community in a way that was previously not possible, so that datasets can become part of the scholarly communication, linked either with traditional outputs or on their own:

Datasets are a significant part of the scholarly record and are being published more and more frequently, either formally or informally... In short, they need to be integrated into the scholarly information system so that authors, readers and librarians can use, find and manage them as easily as they do working papers, journal articles and books. (Green, 2009, p. 13)

This becomes an issue for all concerned in the generation, analysis and storage (and increasingly curation) of data (Borgman, 2007). Scientists, institutions, data centres, users, funders, and publishers all have a part to play in the management of data (Lyon, 2007). 
A recent international collaboration has been set up with the aim of facilitating easier sharing through enabling organisations to register research datasets and assign persistent identifiers to them, so that research datasets can be handled as independent, citable, unique scientific objects.

Viewing data in this way reveals a bias towards the sciences, where datasets are often already fully documented and enabled for sharing. In other fields such as in the social sciences and humanities, the context within which the data is gathered is particularly important for their interpretation and often left undocumented as the data was only intended for use by the researcher who collected it, or close colleagues. Even within the natural sciences, the sharing of data in a highly competitive setting is not without problems (Borgman, 2007, ch. 6).

\section{Integration: Open Publishing Leading to More Integration?}

The second dimension of scholarship was integration, where the discoveries of others are put into context and applied to wider problems. This section will focus on the mechanisms through which scholars publish and communicate their findings and learn about the work of others. In this section we will focus primarily on the journal article, whilst recognizing that conference proceedings and the monograph are still of significant importance in some fields such as computer science and history, respectively. This is because it is journal articles that are currently the site of the greatest tension between the established business models and newer open forms made possible through a move to digital publishing (Cope \& Kalantzis, 2009).

A number of issues converge into what has been labelled a journals crisis (Edwards \& Shulenburger, 2003; Willinsky, 2006; Cope \& Kalantzis, 2009). These include long lag times between submission and publication; increasing subscription costs and the practice of bundling large numbers of journals together and the growing resentment over the reliance of journals on the volunteered labour of the writers, reviewers and editors for the content, which is then sold back to their employers (Harley Acord, Earl-Novell, Lawrence, \& King, 2010).

This is exacerbated by the tendency to replicate the limitations of paper publishing even in digital formats, such as word limits, restrictions on dynamic content and links to datasets. Experiments in the possibilities of the digital format are taking place, such as the Journal of Visualized Experiments (JOVE) in biology, which is a peer-reviewed, PubMed-indexed journal, consisting of videoed contributions. The idea behind JOVE is that video is a more appropriate medium with which to communicate complex experimental techniques and that it reduces the time taken to learn and adopt new ideas. JOVE is an example of the new formats made possible through the adoption of new technologies.

There is also a wider philosophical point that the traditional publishing business model restricts access to those working within the universities and research institutes that can afford to pay the subscriptions, excluding those researchers in other institutions and in particular in lesser developed countries (Willinsky, 2006). The proponents of open publishing argue that making knowledge freely available enhances scholarship to the wider benefit of society.

The peer review process has also begun to be adapted from established traditions in light of changes in the technologies of publication. These changes arise from the ability of readers to copy, append, and comment on the content of an article through the medium of distribution - the online forms of publication. The shift from a series of discrete and disciplined steps in a publication process that ends in a finished product to an ongoing system of regular commentary 
and conversation (post publication peer review) asks interesting questions about the function of peer review. The process of peer review has functioned as a means to ensure quality but there is a sense in which the normative effect of peer review has come to signify the process as being an end in and of itself, rather than the means to an end.

There are a number of modifications to peer review, such as open peer review and publishing or acknowledging the contributions of reviewers to the final text (Cope \& Kalantzis, 2009; Harley et al., 2010). In 2006, the journal Nature ran a debate and experiment with open peer review, which involved making articles that were undergoing the traditional process of peer review available on a publicly accessible server for wider comment, with the reviewers and public comments taken into consideration when deciding on publication. This trial was not particularly successful, with a low take up by authors and a lack of high quality comments and Nature subsequently reverted to the former model.

Despite the possibilities for open publication made possible through a move to digital formats, there is still an inherent conservatism fostered through the current system of recruitment and promotion of scholars, which prioritises traditional outputs (Borgman, 2007; Harley et al., 2010). In addition to this, digital media makes the problem of finding relevant resources among a welter of outputs more difficult, although the solution to this may well take advantage of Web 2.0 type ideas, such as Mendeley or $\underline{\text { Citeulike. }}$

\section{Application: Opening Up the Boundaries Between Academia and the "Real World"}

Academics have been enthusiastic users of many new communication technologies in order to participate in wider global debates relevant to their field. Academic bloggers for example can gain large audiences (for example, Stephen Downes and danah boyd) and through this reach, engage and interact with new audiences. We are seeing the development of a "personal brand" among academics as new technologies allow them to establish an audience that is complementary to their institutional one. For example Open University philosophy lecturer Nigel Warburton has achieved over 5 million downloads of his podcasts and Kansas State University professor Michael Wesch has had over 10 million views of his YouTube video "The Machine is Using Us." A "tweet" from British celebrity Stephen Fry led to over 50,000 hits in one day to an Open University site, whereas a feature on the BBC Radio 4 news led to 2,400 hits on a different site (Clow, 2009). While not directly comparable, this illustrates the power of new technologies.

These kinds of figures far exceed the sales of scholarly books and journal article access; so we can see that new technologies are facilitating access to a new audience that is disintermediating many of the conventional channels. Key to realizing a personal brand online is an attitude of openness. This involves sharing aspects of personal life on social network sites, blogging ideas rather than completed articles, and engaging in experiments with new media.

Blogs, and micro-blog sites like Twitter, enable scholars to communicate with large numbers of followers but this raises important questions about scientific literacy of the general public. In particular, revealing internal debates and uncertainties in scientific discourses can undermine political efforts to solve pressing problems, such as what happened with the recent leaking of email exchanges concerning global warming data that undermined the value of peer review. 


\section{Teaching: Open Education}

It is arguably in Boyer's (1990) fourth function, that of teaching, that we see the biggest impact of digital technologies and open approaches. The digitization of learning and teaching resources means that they are easily reproducible and shareable at a global scale although doing this raises serious challenges for universities used to being the gatekeeper to such knowledge.

The advent of MIT's Open CourseWare project in 2001 initiated the advent of Open Education Resources (OERs). This led to a broad OER movement with many universities embarking on similar projects (such as the OU's OpenLearn ). While there is debate as to the direction, sustainability and impact of the OER movement (e.g. Siemens, 2009; Wiley, 2009) the OER movement has raised the profile of openness in education and whether as publicly funded institutions universities have an obligation to release content freely. This subsection will focus on the impact of the Open Education Resources movement on scholars and scholarship.

With the advent of a wide variety and high quality of freely available academic content online, the individual student is no longer limited by the physical resources they can locate, and the lecturer is therefore no longer regarded as the sole source of knowledge as the learner can pick and chose elements from a variety of courses provided by any number of diverse institutions (Geith, 2008). Whilst there are institutional benefits to making its educational resources freely available, the large-scale projects such as OpenLearn have been made possible through significant external funding, and in the current economic climate some universities, such as Ohio State University have backtracked from the Open Education agenda (McAndrew, Scanlon, \& Clow, 2010). From the individual scholar's point of view using open educational resources allows access to high quality materials although this might require a new skill set in reappropriating these tools to meet local and course specific contexts. There is also the question of recognising and valuing the creation and recreation of these learning resources as academic outputs, in a way that is analogous to the value of producing physical textbooks previously.

\section{Conclusion}

It is clear from the foregoing discussion that new technologies hold out very real possibilities for change across all facets of scholarship. In each case these afford the possibility for new more open ways of working. Academic work has always contained a significant element of collaboration within academia but now it is increasingly easy to collaborate with more colleagues within but also beyond the academy and for the varied products of these collaborations to be available to the widest possible audience.

However, there have been extravagant claims about the transformational potential of computers for almost as long as there have been computers (for a review of earlier claims relating to the introduction of desktop computing see Shields 1995). Whilst it seems inevitable that many scholars will adopt new tools and technologies as they have done in the past it is by no means inevitable that this will transform their work practices or affect the established norms and values of academic work which have remained relatively stable of the years (or if they have changed it has been due to much bigger forces, such as the move from elite to mass participation, introduction of fees etc.).

These new web based technologies are then a necessary, but not sufficient, condition for a radical opening up of scholarly practice. In this sense digital scholarship is more than just using information and communication technologies to research, teach and collaborate, but it is 
embracing the open values, ideology and potential of technologies born of peer-to-peer networking and wiki ways of working in order to benefit both the academy and society. Digital scholarship can only have meaning if it marks a radical break in scholarship practices brought about through the possibilities enabled in new technologies. This break would encompass a more open form of scholarship.

The open scholar "is someone who makes their intellectual projects and processes digitally visible and who invites and encourages ongoing criticism of their work and secondary uses of any or all parts of it--at any stage of its development” (Burton 2009). This is a significant and challenging step for scholars, especially when faced with norms and values that oppose, hinder, or fail to recognize these forms of scholarship.

Whilst it is important to remain critical of much of the hyperbole surrounding new technologies, recognizing that previous technological revolutions have failed to transform most academic work, there is a growing recognition across each element of scholarship that digital tools can lead to new and more open ways of working. This approach calls for future research into those scholars who are embracing the digital scholarship agenda in order to establish the effectiveness and use of these tools, the extent to which this use leads to more open ways of working and to understand the factors facilitating and inhibiting the uptake of digital tools across disciplines. 


\section{References}

Anderson, T. (2009). ALT-C keynote presentation. http://www.slideshare.net/terrya/terryanderson-alt-c-final.

Barjak, F. (2006). The role of the Internet in informal scholarly communication. Journal of the American Society for Information Science, 57(10), 17.

Blin, F., \& Munro, M. (2008). Why hasn't technology disrupted academics' teaching practices? Understanding resistance to change through the lens of activity theory. Computers and Education 50(2), 475-490.

Borgman, C. L. (2007). Scholarship in the digital age: Information, infrastructure, and the Internet. Cambridge, MA: MIT Press.

Boyer, E. L. (1990). Scholarship reconsidered: Priorities of the professoriate. Princeton, N.J: Carnegie Foundation for the Advancement of Teaching.

Burton, G. (2009). The open scholar. Academic Evolution. Retrieved from http://www.academicevolution.com/2009/08/the-open-scholar.html

Clow, D. (2009). @stephenfry 20x better than BBC News. Doug Clow's imaginatively titled blog (Blog). Retrieved from http://dougclow.wordpress.com/2009/03/31/new-media-betterfor-new-media/

Conole, G. (2004). E-learning: The hype and the reality. Journal of Interactive Media in Education, 12.

Cope, B., \& Kalantzis, M. (2009). Signs of epistemic disruption: Transformations in the knowledge system of the academic journal. First Monday, 14(4).

Edwards, J., \& Shulenburger, D. (2003). The high costs of scholarly journals (and what to do about it). Change, 35(6), 10.

Foster, I. (2006). 2020 computing: A two-way street to science's future. Nature, 440, 419.

Fry, J. (2004). The cultural shaping of ICTs within academic fields: Corpus-based linguistics as a case study. Literary and Linguistic Computing, 19(3), 303-319.

Fry, J. (2006). Scholarly research and information practices: A domain analytic approach. Information Processing and Management, 42, 299-316.

Fry, J., \& Talja, S. (2007). The intellectual and social organization of academic fields and the shaping of digital resources. Journal of Information Science, 33(2), 115-33.

Galison, P., \& Hevly, B. W. (1992). Big science: The growth of large-scale research. Stanford, CA: Stanford University Press.

Green, T. (2009). We need publishing standards for datasets and data tables. OECD.

Harley, D., Acord, S. K., Earl-Novell, S., Lawrence, S., \& King, C. (2010). Assessing the future landscape of scholarly communication: An exploration of faculty values and needs in seven disciplines. Berkeley, CA: UC Berkeley: Center for Studies in Higher Education.

International Federation of the Phonographic Industry (IFPI). (2010). Digital music report. London: International Federation of the Phonographic Industry. Retrieved from http://www.ifpi.org/content/section_statistics/index.html 
Kling, R., \& McKim, G. (2000). Not just a matter of time: Field differences and the shaping of electronic media in supporting scientific communication. Journal of the American Society for Information Science, 51(14), 14.

Lyon, L. (2007). Dealing with data: Roles, rights, responsibilities and relationships. Bath: UKOLN. Retrieved from http://www.ukoln.ac.uk/ukoln/staff/e.j.lyon/publications.html

McAndrew, P., Scanlon, E., \& Clow, D. (2010). An open future for higher education. EDUCAUSE Quarterly, 33(1).

Oblinger, D, \& Oblinger, J. (2005). Is it age or IT: First steps toward understanding the Net Generation. In D. Oblinger \& J. Oblinger (Eds.), Educating the Net Generation. Retrieved from EDUCAUSE http://www.educause.edu/educatingthenetgen

Pearce, N. (Forthcoming). A case study of technology adoption by researchers: Web and escience infrastructures to enhance research. Information, Communication and Society.

Peters, M. A. (2009). Academic publishing and the political economy of education journals. In B. Cope \& A. Phillips (Eds.), The future of the academic journal. Oxford: Chandos.

Pieri, E. (2009). Sociology of expectation and the e-social science agenda. Information, Communication and Society, 12(7), 1103-1118.

Prensky, M. (2001). Digital natives, digital immigrants. On the Horizon, 9(5), 1-6.

Rosenzweig, R. (2007). Can history be open source? Wikipedia and the future of the past. Journal of American History, 93(1), 117-146.

Shields, M. A. (1995). The legitimation of academic computing in the 1980s. In M. A Shields (Ed.), Work and technology in higher education: The social construction of academic computing (pp. 161-187). Hove, UK: Lawrence Erlbaum Associates.

Shields, M. A. ( Ed.), (1995). Work and technology in higher education: The social construction of academic computing. Hove, UK: Lawrence Erlbaum Associates.

Siemens, G. (2009). Open isn't so open anymore. Connectivism. Retrieved from http://www.connectivism.ca/?p=198

Tapscott, D., \& Williams, A. D. (2010). Innovating the 21st-century university: It's time! EDUCAUSE Review, 45(1), 16-29.

Walsh, J. P., Kucker, S., Maloney, N. G, \& Gabbay, S. (2000). Connecting minds: Computermediated communication and scientific work. Journal of the American Society for Information Science, 51(14), 1295-1305.

Whitley, R. (1984). The intellectual and social organization of the sciences. Oxford: Oxford University Press.

Wiley, D. (2009). The golden ratio of OER. Iterating towards openness (Blog). Retrieved from http://opencontent.org/blog/archives/1146\#axzz0nvFUkwxQ

Willinsky, J. (2006). The access principle: The case for open access to research and scholarship. Cambridge, MA: MIT Press. 
Wouters, P., \& Beaulieu, A. (2006). Imagining e-science beyond computation. In C. Hine (Ed.), New infrastructures for knowledge production: Understanding e-science (pp. 48-70).

Michigan: Idea Group. 